\title{
Detecting Large-scale Intracontinental Slow-slip Events (SSEs) Using Geodograms
}

\section{Brian Wernicke ${ }^{1}$ and James L. Davis ${ }^{2}$}

\section{INTRODUCTION}

Since the advent in the 1980s of GPS networks to monitor crustal velocity fields, interpretations of geodetic data have generally been based on maps of Earth's surface showing average horizontal site velocity over a specified period of time and plots showing velocity gradients as a function of a position coordinate (e.g., Donnellan et al. 1993; Bennett et al. 1999). For continuous networks, these plots are typically supplemented by time series of position in order to assess the importance of timedependent or transient behavior (Bock et al. 1993; Hudnut et al. 2002). Thus far, regional transient motions have been revealed by plotting position time series from multiple sites on a common time axis. These plots have been effective in demonstrating the existence of slow-slip events (SSEs) on subduction megathrust interfaces around the globe (e.g., Miller et al. 2002; Melbourne et al. 2005; Schwartz and Rokosky 2007). A largescale intraplate SSE in the northern Basin and Range Province that occurred between 1999 and 2005 was initially identified by plotting continuous time series with a vertical time axis, arranged according to a spatial position coordinate for each site (Davis et al. 2006, their Figure 3A).

Because transient motions are by definition changes in velocity, however, the spatial coherence and magnitude of velocity changes are most directly addressed by plotting the time dependence of velocity rather than position. Here, we describe a method for calculating velocity time series, and then we use these to construct a "geodogram" from raw continuous GPS time series. The new time series reveal additional transient motions from 2005 to 2007 that are interpreted to reflect the onset of a new SSE beginning in late 2006.

\section{CONSTRUCTING GEODOGRAMS}

We started with an analysis of Basin and Range Geodetic Network (BARGEN) data using methods described in Bennett et al. (2002). We used the decade-long continuous time series for the first 18 sites installed in BARGEN in 199697 (Wernicke et al. 2000), supplemented with shorter time series for five additional sites (GABB, BAMO, TOIY, MONI,

1. Division of Geological and Planetary Sciences, California Institute of Technology, Pasadena, California

2. Harvard-Smithsonian Center for Astrophysics, Cambridge, Massachusetts and SPIC) installed more recently (Davis et al. 2006; Wernicke et al. 2008) (Figure 1). Previous analyses of this network (Bennett et al. 2002; Davis et al. 2006; Wernicke et al. 2008) show that average horizontal velocities (relative to a North American reference frame) rise from near zero on the eastern side of the network to about $3 \mathrm{~mm} / \mathrm{yr}$ oriented due west near the Nevada-Utah border, indicating crustal extension in the eastern Basin and Range (Figure 1). Average velocities remain relatively constant across eastern Nevada, progressively rotating northwestward and increasing in magnitude up to $12 \mathrm{~mm} /$ yr across western Nevada, accommodating both extension and right-lateral shear associated with the Pacific-North America transform plate boundary to the west (e.g., Bennett et al. 2003; Hammond and Thatcher 2004). Position time series over the entire decade of data indicate significant secular changes in velocity (Davis et al. 2006), such as in the east component of motion for site EGAN (Figure 2A).

The first step in our procedure is the application of an analysis algorithm using a Kalman filter that allows for stochastic variations in both velocity and seasonal signals. The time series are long enough that the seasonal signals are not well represented by pure spectral components (typically annual plus semiannual), and this spectral variability must be taken into account (e.g., Bennett 2008) (Figure 2A). The Kalman filter processor enables stochastic variations in the amplitudes of sinusoidal terms with annual and semiannual periods, as well as in velocity. The stochastic variations are modeled as randomwalk processes.

The red curve in Figure 2A shows the estimated model position from the Kalman filter for the EGAN horizontal position time series. For illustration, Figure $2 \mathrm{~B}$ shows the time series and model with the seasonal terms removed. It can be seen that the Kalman filter successfully accounts for the variable amplitudes seen in Figure 2A. Inspection of Figure 2A suggests that the "velocity changes" associated with the seasonal variations are large, and if included in the analysis would seriously hamper any attempt to estimate tectonic or other velocity changes through time.

In Figure 2C, we show the estimated velocity solution from the Kalman filter. The filter has been run both in the forward and reverse directions, and the random-walk model leads to a smooth variation of velocity with time. We have indicated, in Figures $2 \mathrm{~B}$ and $\mathrm{C}$, epochs of large velocity changes so that they can be compared in both the (seasonal-variation-corrected) 


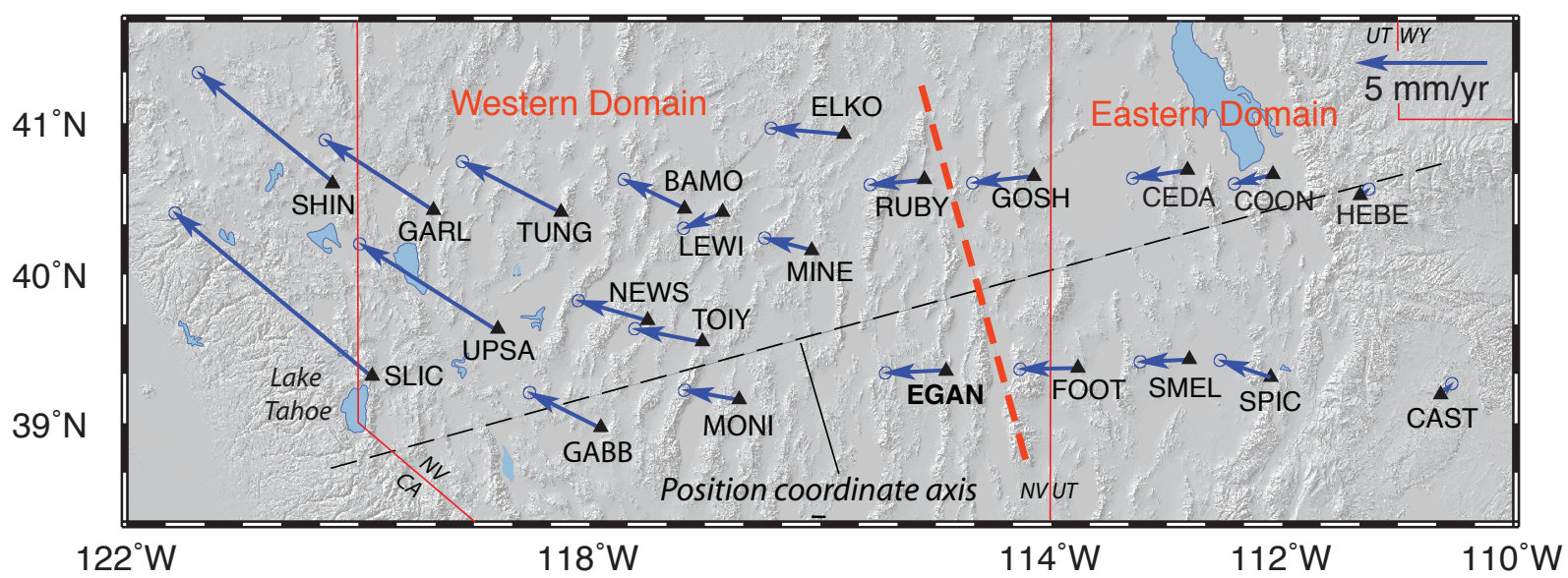

A Figure 1. Map showing average velocity field (ca. 1997-2007) with $1 \sigma$ error ellipses of BARGEN GPS sites near latitude $40^{\circ} \mathrm{N}$, after Wernicke et al. (2008).

(A)
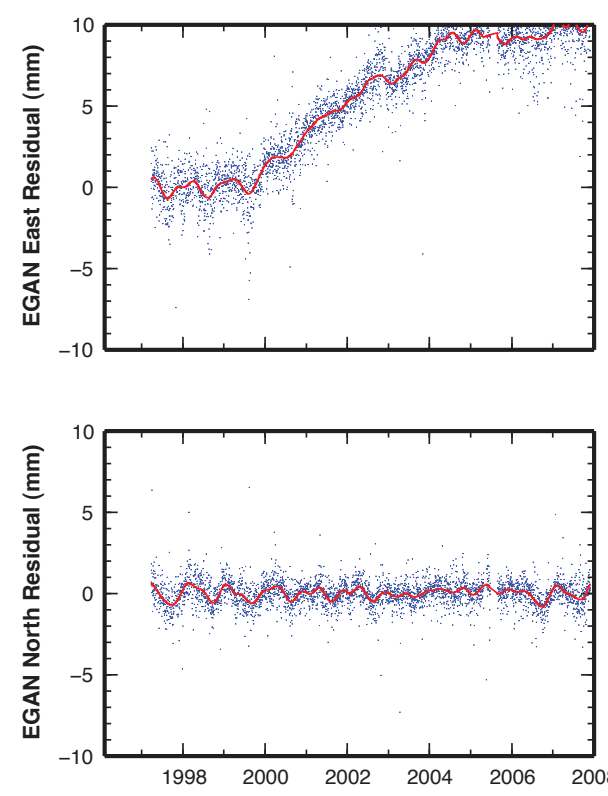

(B)
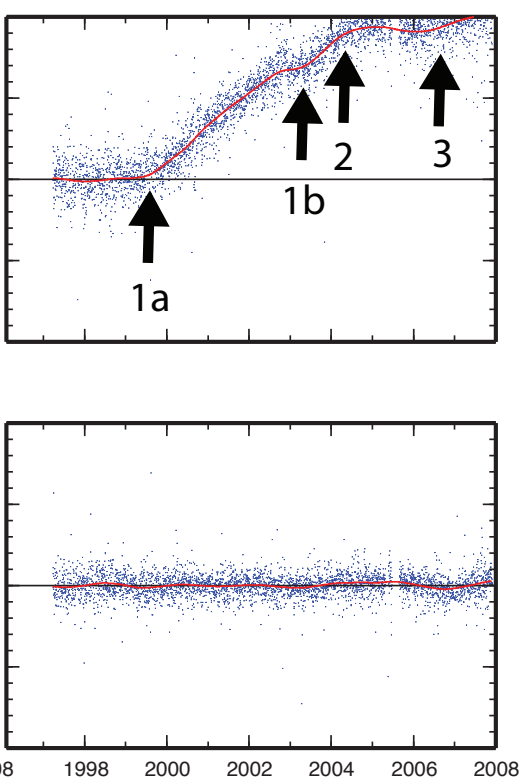

(C)
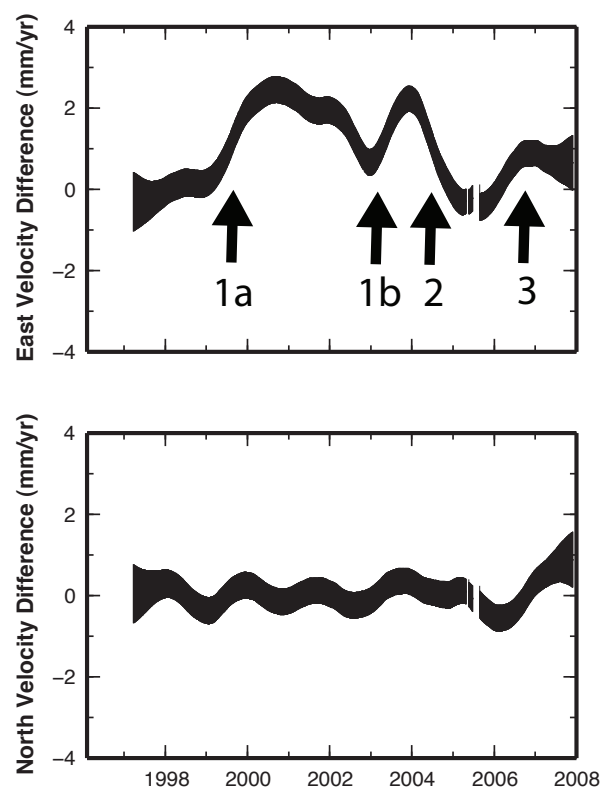

- Figure 2. A) Unfiltered time series of east (upper) and north (lower) components of position of site EGAN, relative to its average position prior to 2000.0. The model determined using the Kalman filter described in the text is shown with a red line. B) Same as A, with seasonal signals removed from the data and model. C) Velocity time series derived from the filter analysis for site EGAN; width of curve reflects $1 \sigma$ error limits.

position time series and the velocity time series. The error bars shown in Figure 2C are the one-standard-deviation uncertainties from the filter run. As such, they are largely controlled by the random-walk variance rate of $1 \mathrm{~mm}^{2} / \mathrm{yr}^{3}$ used to model the velocity variations.

The last step in construction is to plot all of the velocity time series in the network with respect to a position coordinate (Figure 3). In this case, we chose a nominal position coordinate by projection onto the direction $\mathrm{N} 68^{\circ} \mathrm{E}$, roughly normal to the Pacific-North America plate boundary to the west and normal to a geographic boundary between sites that exhibit pronounced changes in velocity ("western domain," Figure 1) versus those that do not ("eastern domain," Figure
1) (Wernicke et al. 2008). We used contrasting colors under the curves for velocity variations that reflect either high (red) and low (blue) west velocity, or high (blue) and low (red) north velocity, relative to the average velocity for the whole time series. The polarity of the east velocity variations was chosen to be approximately consistent with the position coordinate, such that higher west velocity is shown toward the left (west) side of the diagram, and slower velocity to the right (east).

\section{DISCUSSION}

For site EGAN, the filtered east position and velocity time series show that beginning in late 1999 (event labeled "1a" 
Distance Along $\mathrm{N} 67.5^{\circ} \mathrm{E}$ (degrees)

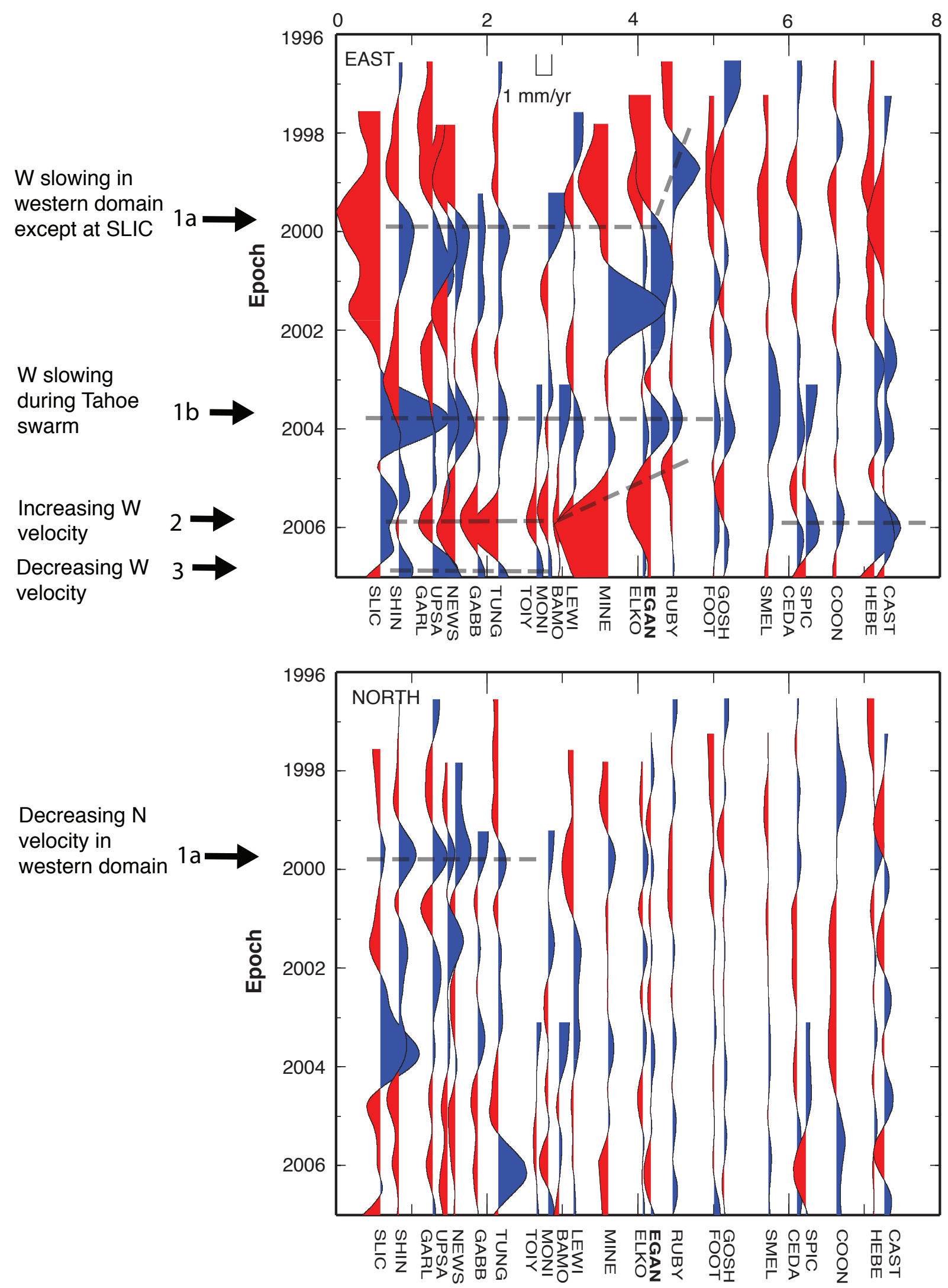

$\Delta$ Figure 3. Velocity geodograms for BARGEN sites shown in Figure 1. See discussion in text for events labeled 1, 2 and 3. Dashed lines show regionally coherent events discussed in text. 
in Figures 2B, 2C and 3), EGAN's velocity relative to North America slowed by $2 \mathrm{~mm} / \mathrm{yr}$ (depicted as an increase in east velocity on Figures 2 and 3, deflecting its curve on the geodogram to the right), from an initial velocity of $4 \mathrm{~mm} / \mathrm{yr}$ westward relative to North America down to $2 \mathrm{~mm} / \mathrm{yr}$. In late 2003 its velocity again slowed briefly (event $1 \mathrm{~b}$ ) before accelerating back up to its earlier west velocity in 2004 (event 2).

Velocity anomalies similar to those at site EGAN are readily apparent on most of the continuous sites on the geodogram. Decreasing west velocity, and for western sites, north velocity is apparent mainly in Nevada, with site RUBY slowing first in 1998-99, followed by most other sites in the western domain by late 2000, with the notable exception of SLIC (event 1a, Figure 3). By comparison, eastern domain sites (FOOT through CAST on the right-hand side of Figure 3) remained relatively steady, resulting in east-west crustal shortening in eastern Nevada (Wernicke et al. 2008). After 2001.5, slowing remains pronounced near the center of the network at sites EGAN and MINE, but not at sites to the west.

Following a relatively incoherent increase in west velocity for some sites after 2001.0, in 2003 coherent slowing is apparent network-wide, most dramatically at site SLIC (event $1 \mathrm{~b}$, Figures 2 and 3), which prior to this time had not showed evidence of slowing (Davis et al. 2006). The event at SLIC is temporally correlative with a nearby earthquake swarm in the Lake Tahoe area near Moho depth and is interpreted as resulting from a magmatic injection event at the base of the crust (Smith et al. 2004). The geodogram clearly shows that the event was not restricted to the Lake Tahoe region and appears to involve slowing as far to the east as Utah. The temporal correlation of this event with the Tahoe swarm is the strongest evidence that the observed motions are tectonic in origin (Smith et al. 2004). This event in particular is relatively obscure in position time series (e.g., Davis et al. 2006, Figure 3A), but is quite pronounced on the geodogram.

In 2005, a pronounced increase in west velocity is apparent across Nevada (event 2, Figures 2 and 3). This event is most apparent in western sites that speed up $2 \mathrm{~mm} / \mathrm{yr}$ or more persisting well into 2006, and is anti-correlated with slowing of eastern domain sites from 2005.5 to 2006.5. Indeed, near 2006.0, the region near the Nevada-Utah border appears to be in a state of hyperextension, with velocities on either side at their most divergent values of the decade, perhaps as great as 4 $\mathrm{mm} / \mathrm{yr}$ faster than average. The onset of event 2 shows the best evidence on the geodogram of propagation, beginning near 2004.5 at site RUBY but not until after 2005.0 in most sites between NEWS and SLIC (Figure 3). During this event, velocities returned to values close to those prior to event 1 , signaling an end to generally slow west velocity. However, the onset of renewed slowing (event 3 ) is apparent near the end of 2007.

The primary velocity variations of events $1 \mathrm{a}, 1 \mathrm{~b}$, and 2 have been previously interpreted to reflect an SSE of extraordinary scale on an intraplate, subhorizontal decoupling horizon or "megadetachment" beneath western domain sites, such that westward slowing and contractile strain near the Utah-Nevada border is a reflection of top-east strain release on the buried interface (Davis et al. 2006; Wernicke et al. 2008). Event 3 marks a return of slowing and hence is interpreted to reflect the return of strain release across much of the interface.

As is also evident from Figure 3 there is an unmistakable variation in virtually all velocity time series with a period of about two years that is not apparent in position time series, because its amplitude is much smaller than both seasonal and tectonic signals. Given its coherence across the entire span of the network, we conclude that this is not simply an artifact of the filtering process. Its amplitude is at least of order $0.5 \mathrm{~mm} /$ yr, as suggested by time series that otherwise show very little variation, for example the north component of site EGAN (Figure 2C) or the east components of sites FOOT, CEDA, and COON (Figure 3). The large strains evident in these variations indicate that they are not a reference-frame effect.

There are at present no known processes originating within the solid earth with biennial forcing, but the tropospheric biennial oscillation (TBO) is well documented and has been interpreted to result from an interaction between ENSO (El Nino-Southern Oscillation) and the Asia-Australian monsoon (e.g. Kim and Lau 2009). Detailed analysis of a potential link between this complex phenomenon and the geodetic data, including potential forcing of the tectonic system, is well beyond the scope of this paper. The long-wavelength load cycles in the ocean basins occur at similar rates and could plausibly result in differential horizontal motions within the continents on the order of $1 \mathrm{~mm} / \mathrm{yr}$. This speculative but intriguing hypothesis, if correct, may eventually lead to an improved understanding of both climatic and tectonic signals apparent in all continuous GPS data. $\mathbf{z}$

\section{ACKNOWLEDGEMENTS}

This research was supported by NSF Grants EAR-0810328 (BW) and EAR-0809195 (JLD), and by the Caltech Tectonics Observatory. We are grateful to D. L. Anderson and D. J. Stevenson for alerting us to the TBO as a plausible origin of the quasi-biennial signal on the geodogram.

\section{REFERENCES}

Bennett, R. A. (2008). Instantaneous deformation from continuous GPS: Contributions from quasi-periodic loads. Geophysical Journal International 174 (3), 1,052-1,064.

Bennett, R. A., J. L. Davis, J. E. Normandeau, and B. P. Wernicke (2002). Space geodetic measurements of plate boundary deformation in the western U.S. Cordillera. In Plate Boundary Zones, ed. S. A. Stein and J. T. Freymuller, 27-55. Geodynamics Series vol. 30. Washington, DC: American Geophysical Union.

Bennett, R. A., J. L. Davis, and B. P. Wernicke (1999). Present-day pattern of Cordilleran deformation in the western United States: Geology 27, 371-374.

Bennett, R. A., B. P. Wernicke, N. A. Niemi, A. M. Friedrich and J. L. Davis (2003). Contemporary strain rates in the northern Basin and Range province from GPS data. Tectonics 22, TC001355.

Bock, Y., D. C. Agnew, P. Fang, J. F. Genrich, T. A. Herring, K. W. Hudnut, et al. (1993), Detection of crustal deformation from the Landers earthquake sequence using continuous geodetic measurements, Nature 361 (6,410), 337-340. 
Davis, J. L., B. P. Wernicke, S. Bisnath, N. A. Niemi and P. Elosegui (2006), Subcontinental-scale crustal velocity changes along the Pacific-North America plate boundary, Nature, 441 (7,097), 1,131$-1,134$.

Donnellan, A., B. H. Hager, R. W. King and T. A. Herring (1993). Geodetic measurement of deformation in the Ventura Basin region, southern California. Journal of Geophysical Research-Solid Earth 98(B12), 21,727-21,739.

Hammond, W. C. and W. Thatcher (2004). Contemporary tectonic deformation of the Basin and Range province, western United States: 10 years of observation with the Global Positioning System, Journal of Geophysical Research-Solid Earth 109, B08403.

Hudnut, K. W., N. E. King, J. E. Galetzka, K. F. Stark, J. A. Behr, A. Aspiotis, S. van Wyk, R. Moffitt, S. Dockler and F. Wyatt (2002). Continuous GPS observations of postseismic deformation following the 16 October 1999 Hector Mine, California, earthquake (Mw 7.1), Bulletin of the Seismological Society of America 94 (4), $1,403-1,422$.

Kim, K. M., and K. M. Lau (2001). Dynamics of monsoon-induced biennial variability in ENSO, Geophysical Research Letters 28 (2), 315-318.

Melbourne, T. I., W. M. Szeliga, M. M. Miller, and V. M. Santillan (2005). Extent and duration of the 2003 Cascadia slow earthquake. Geophysical Research Letters 32, L04301.

Miller, M. M., T. Melbourne, D. J. Johnson and W. Q. Sumner (2002). Periodic slow earthquakes from the Cascadia subduction zone. Science 295 (5564), 2,423--2,423.
Schwartz, S. Y., and J. M. Rokosky (2007). Slow slip events and seismic tremor at circum-pacific subduction zones: Reviews of Geophysics 45, RG3004.

Smith, K. D., D. von Seggern, G. Blewitt, L. Preston, J. G. Anderson, B. P Wernicke and J. L. Davis (2004). Evidence for deep magma injection beneath Lake Tahoe, Nevada-California. Science 305 (5688), $1,277-1,280$.

Wernicke, B., J. L. Davis, N. A. Niemi, P. Luffi and S. Bisnath (2008). Active megadetachment beneath the western United States. Journal of Geophysical Research-Solid Earth 113, B11402.

Wernicke, B., A. M. Friedrich, N. A. Niemi, R. A. Bennett and J. L. Davis (2000). Dynamics of plate boundary fault systems from Basin and Range Geodetic Network (BARGEN) and geologic data. GSA Today 10, 1-7.

$$
\begin{array}{r}
\text { Division of Geological and Planetary Sciences } \\
\text { California Institute of Technology, } \\
\text { Mail Code 100-23, } \\
\text { Pasadena, California } 91125 \text { U.S.A. } \\
\text { brian@gps.caltech.edu } \\
\text { (B.W.) }
\end{array}
$$

Harvard-Smithsonian Center for Astrophysics 60 Garden Street, MS 42 Cambridge, Massachusetts 02138 U.S.A. jdavis@cfa.harvard.edu (J.L.D.) 